\section{Could fracking creep under the radar?}

As sometime energy advisers to the UK government, we are concerned that fracking of unconventional oil and gas formations risks being classed as conventional hydrocarbon exploration, a relatively insignificant and unobtrusive cottage industry in the United Kingdom. This results from the government using legally binding definitions of unconventional oil and gas (UOG) resources and of highvolume hydraulic fracturing (HVHF, or fracking) that have little rational or scientific basis.

The government classes shales as unconventional sources of oil and gas, whereas limestone and sandstone rocks are conventional sources. This overlooks unconventional 'tight' (low-permeability) limestone and sandstone. Although there is no universal definition of UOG, the consensus is that the hydrocarbons are held in tight rock (permeability less than 0.1 millidarcies), are unevenly concentrated and widely dispersed, and can be extracted by acid or HVHF.

The UK definition of HVHF is based on how much water is needed for extraction: 10,000 cubic metres or more per well. But the US threshold for HVHF of shale, based on roughly 264,000 fracked US wells, is about $2,000 \mathrm{~m}^{3}$ of extraction water per oil well and 2,500 $\mathrm{m}^{3}$ per gas well (T. J. Gallegos et al. Water Resour. Res. 51, 5839-5845; 2015).

Current exploratory drilling in the United Kingdom's Weald Basin is registered as 'conventional' because the hydrocarbon licensees are testing thin limestone layers in the shale and are not yet fracking. Assuming the UK licensees start HVHF, they can then in principle claim that it is conventional hydrocarbon production by keeping the fracking fluid volume to less than $10,000 \mathrm{~m}^{3}$ per well, which would evade environmental obligations specified in the 2015

UK Infrastructure Act.

David Smythe Ventenac en

Minervois, France.

Stuart Haszeldine University of

Edinburgh, UK.

david.smythe@glasgow.ac.uk

\section{Fake serum has telltale fingerprint}

Surging sales of counterfeit fetal bovine serum are threatening the safety of pharmaceuticals and vaccines, particularly in China (see Nature 545, 148-150; 2017). To help tackle the problem, GE Healthcare in the United States has launched a screening programme with the product-traceability firm Oritain in Dunedin, New Zealand, to swiftly pinpoint the country of origin of serum samples and provide an indicator of the likelihood of contamination.

As a by-product of the meat industry, fetal bovine serum may contain infectious agents such as that responsible for bovine spongiform encephalopathy. The risk varies by country, depending on disease prevalence. Users therefore prefer serum from lowrisk countries such as Australia, New Zealand or the United States. This drives up the price of such premium material and creates an incentive to mislabel the country of origin for fetal bovine serum from higher-risk countries.

Counterfeit samples carrying fake labels are easily spotted. Authentic bottles refilled with bogus material are not, which is where our test comes in (see go.nature.com/2w7dbth). As a result of the food and water they consume, cows carry a distinct trace-element fingerprint from their country of origin. The test identifies the fingerprint by screening it against reference standards.

Our programme could be used to complement the existing paperwork system for verifying authenticity.

Robert Curry GE Healthcare

Life Sciences, Marlborough,

Massachusetts, USA.

robert.curry@ge.com

Competing financial interests

declared; see go.nature.com/2fmuzeh.

\section{Rename the impact factor}

There have been several failed attempts to retire the journal impact factor (see also R. J. Roberts Nature 546, 600; 2017). However, there can be value in knowing which journals are publishing papers of immediate wide interest. I therefore suggest that, rather than repealing or replacing the impact factor, its producers should rename it to reflect its intended function more accurately.

The problem lies not with the impact factor's calculation - apart from flaws such as the criteria for inclusion or exclusion - but in its misleading name, which results in its misuse. It would be better classed as an average 'short-term citability factor' that is valid for two years after publication. Journals, authors, grant agencies and institutions could then decide whether to compete in this category.

Alternatively, peer-reviewed journals could choose to be compared using other indices, such as a long-term (say, 20-year) citability factor and/or total citations over time. This might encourage editors to select papers purely on quality and originality, as they used to, irrespective of a paper's potential for popularity.

Academic leaders, administrators, policymakers and funding agencies would then be free to decide whether to base their assessments on publications in journals with short- or longterm popularity and citability.

Ajit Varki University of California, San Diego, USA. alvarki@ucsd.edu

\section{Signing up to safe water for billions}

The Charter of the Geneva Actions on Human Water Security last month committed its founding signatories to global action on water. They pledged to provide access to safely managed drinking water and basic sanitation services for billions of people worldwide, in line with the United Nations Sustainable Development Goals of 2015.

The signatories comprise 55 water experts and practitioners from 23 countries, including 12 UNESCO chairs in water-related topics (https://genevaactions.org). They have signed up to three global actions: to secure the delivery of safe water to meet people's basic needs; to improve the condition of watersheds, streams, rivers and aquifers; and to organize better water planning, management and governance.

Inspired by the Green Climate Fund (www.greenclimate.fund/ home), the signatories highlight the urgent need for a Global Human Water Security Fund to invest in these water actions. The fund would invest the equivalent of one cent per person per day worldwide, or US\$27 billion per year. This represents about one-quarter of the total annual investments required to meet the 2030 Sustainable Development Goal on water (see go.nature. com/2hnrzlv).

Quentin Grafton The Australian National University, Acton, Australia.

Asit K. Biswas, Cecilia

Tortajada National University of Singapore, Singapore. quentin.grafton@anu.edu.au

CONTRIBUTIONS

Correspondence may be sent to correspondence@ nature.com after consulting the author guidelines at http://go.nature.com/ cmchno 